\title{
KAJIAN PENDIDIKAN KARAKTER BERBASIS KEARIFAN LOKAL PADA CERITA RAKYAT "NYI ANDAN SARI DAN KI GURU SOKA”
}

\author{
Yustina Dwinuryati ${ }^{\mathrm{a} *}$, Andayani ${ }^{\mathrm{b}}$ \\ ${ }^{a}$ Mahasiswa Prodi Pendidikan Bahasa Indonesia, \\ Pascasarjana FKIP Universitas Sebelas Maret Surakarta, Indonesia \\ ${ }^{b}$ Dosen Pendidikan Bahasa Indonesia, \\ Pascasarjana FKIP Universitas Sebelas Maret Surakarta, Indonesia \\ Jalan Ir. Sutami 36 A, Surakarta, 57126
}

\begin{abstract}
ABSTRAK
Terdapat beragam folklor atau cerita rakyat yang mengandung nilai kearifan lokal. Cerita rakyat mengandung banyak relevansi dengan pembentukan budi pekerti atau karakter. Tujuan penelitian ini mendeskripsikan manfaat folklor sebagai salah satu pembentukan karakter. Metode yang digunakan dalam penelitian ini adalah kualitatif deskriptif. Data penelitian berupa dokumen cerita rakyat berjudul Nyi Andan Sari dan Ki Guru Soka dan wawancara dengan informan yang kemudian ditranskrip dalam bahasa tulis. Analisis data menggunakan analisis interaktif Untuk memvalidasi data digunakan teknik triangulasi metode dan review informan. Dari penelitian yang dilakukan, ditemukan sepuluh karakter yang muncul dari cerita tersebut. Karakter yang ditemukan yaitu religious, kedisiplinan, keingintahuan yang kuat, kerja keras, toleransi, , mandiri, , semangat kebangsaan, bersahabat, peduli sosial dan tanggung jawab. Setiap karakter yang muncul bermula dari cerita yang terdapat dalam folklor tersebut. Nilai religious dilihat dari kebersediaan bertapa oleh Ki Guru Soka untuk menemui Tuhan agar mendapatkan pencerahan dalam kehidupannya. Meskipun dalam pertapaannya tersebut ia mendapatkan berbagai ancaman, godaan, gangguan dari berbagai bentuk, ia tetap memiliki kekuatan hati untuk melihat ke depan dan tujuannya. Hal ini patut dicontoh, karena saat ini manusia banyak yang sudah tidak tahan godaan, seperti halnya korupsi, pembunuhan, pemerkosaan, dan bentuk kejahatan lainnya. Sebagian dari itu mampu menunjukkan ketidakkuatan pada gangguan bersifat duniawi.
\end{abstract}

Kata Kunci: folklor, karakter, Nyai Andan Sari dan Kyai Soka

\begin{abstract}
There are many folklores that having local wisdom. Foklores posses many values of character. The purpose of the research is to portray the function of folklore to build character. This is a qualitative research applying the descriptive method. The data of the research is a folklore entitled Nyi Andan Sari dan Ki Soka and the transcript of the interview with the informant. The technique of data analysis applied in the study is the joint model of analysis. Data validation applied is triangulation method and informant review. The result of the research is that there are ten figures in the story, namely religious, tolerant, discipline, hard working, independent, curious, nationalist, friendship, social awareness and responsibility. The characters show in the description of the story. The religious character can be viewed from the willingness of Ki Guru Soka to meditate to meet the God to get the enlighten in his life. In his meditation he got a lot of disturbance in various forms, he still has power to keep his goal. It is a good example because nowadays there are many people that doing deeds, for example things such as corruption, murder, rap, and other crimes. It shows the inability of people to face the everyday problems.
\end{abstract}

Keywords: : folklore, character, Nyai Andan dan Kyai Soka

\footnotetext{
* Penulis Koresponden

E-mail address: iyang.yustina@yahoo.com doi:
} 


\section{PENDAHULUAN}

Peningkatan mutu pendidikan merupakan suatu upaya yang sangat penting dalam pelaksanaan pendidikan, khususnya di sekolah (Dirman dan Cicik Junarsih, 2014:1). Pembelajaran di sekolah harus mencerminkan usaha seperti yang diamanahkan dalam tujuan pendidikan nasional yakni mengembangkan potensi peserta didik agar menjadi manusia yang beriman dan bertaqwa kepada Tuhan Yang Maha Esa, berakhlak mulia, sehat, berilmu, cakap, kreatif, mandiri, dan terampil serta bertanggung jawab. Pembelajaran juga harus mampu mendorong peserta didik untuk terlibat secara aktif dalam pembelajaran, sehingga mereka mampu mengembangkan dirinya dengan melengkapi berbagai keterampilan yang diperlukan.

Namun, kenyataannya selama ini belum sepenuhnya memenuhi harapan. Kasus tawuran antarpelajar, kekerasan, pembunuhan bahkan korupsi masih sering diberitakan di berbagai media baik cetak ataupun elektronik. Kenyataan ini menunjukkan bahwa tujuan pendidikan kita sesuai dengan harapan. Seharusnya, pendidikan tidak hanya sekadar menghasilkan manusia yang akan akan ilmu dan pengetahuan, namun juga memiliki budi pekerti yang luhur dalam bermasyarakat, berbangsa, dan bernegara (Safitri, 2015:174).

Kenyataan tersebut mendorong berbagai pihak untuk selalu mengevaluasi dan memperbaiki kualitas pendidikan kita. Lembaga pendidikan diharapkan tidak saja mencetak generasi unggul di bidang akademik, namun juga menghasilkan generasi yang berkarakter kuat, berbudi pekerti mulia. Menurut Kesuma, Triatna, Permana (2013:5) pendidikan karakter sejatinya merupakan pembelajaran yang mengarah pada penguatan dan pengembangan perilaku anak secara utuh yang didasarkan pada suatu nilai tertentu yang dirujuk oleh sekolah.

Pernyataan di atas mengandung makna bahwa pendidikan karakter merupakan pendidikan yang terintegrasi dengan pembelajaran yang terjadi pada semua mata pelajaran. Penyelenggaraan pendidikan karakter menjadi mutlak untuk dilaksanakan, salah satunya dapat dilakukan dengan menggali kearifan lokal melalui cerita rakyat/ folklor yang terdapat di suatu wilayah. Hal ini dilakukan mengingat hampir di setiap wilayah di tanah air memiliki cerita rakyat/ folklor . Seperti dikatakan Marsono (2007: 182) bahwa masingmasing etnik nusantara memiliki banyak jenis kearifan lokal. Hal itu sejalan dengan pendapat Ilahi (2014:83) yang menyatakan bahwa dalam konteks kelembagaan di sekolah, pendidikan budi pekerti atau karakter sebisa mungkin berpijak pada warisan kebudayaan yang menjadi nilai-nilai luhur dalam pembentukan manusia yang bermartabat dan berkeadaban.

Terdapat banyak cerita rakyat yang merupakan bentuk sebuah warisan dari kearifan lokal milik bangsa Indonesia. Cerita rakyat bisa muncul dari berbagai kalangan masyarakat, termasuk persebarannya tidak hanya di satu wilayah tertentu. Tokoh yang dihadirkannya sangat beragam, mulai dari binatang, manusia, dewa-dewa, bahkan makhluk halus. Ceritanya pun kadang merupakan gabungan antara manusia dengan binatang, seperti yang diungkapkan oleh Alua (2015:711) "In folk myths, it was writen that usually, the humans were born by the relation of animals have spesial abilities than other"

Selain itu karakter tokohnya sangat jelas, ada yang berkarakter datar, terbelah antara hitam dan putih atau baik dan buruk. Hal ini berdasarkan amanat yang ingin disampaikan. Jadi pesan moral dalam dongeng bisa berbentuk nasihat atau kritikan secara implisit terhadap manusia yang memiliki perilaku jahat (Nurgiyantoro, 2005:200). Dongeng diciptakan salah satunya sebagai sarana penyaluran ajaran atau pemahaman tentang ajaran moral, pemahaman tentang hidup kepada pembacanya.

Dongeng/ cerita rakyat/ folklor merupakan wujud budaya bersama yang bersifat secara turun temurun dan keberadaanya tersebar di berbagai daerah (Dananjaya, 2002:2). Terdapat empat fungsi foklor, yaitu (1) sebagai sistem proyeksi; (2) sarana untuk mengesahkan aturan-aturan dan lembaga kebudayaan; (3) alat pendidik anak; (4) sarana penjaga norma agar dipatuhi oleh masyarakatnya (Borton dalam Dananjaya, 2002: 19).

Nyatalah bahwa folklor baik dijadikan sebagai bahan bacaan untuk membentuk karakter peserta didik saat ini. Pendidikan karakter merupakan usaha untuk menumbuhkan nilai dan norma berdasarkan budaya bangsa yang sesuai dengan aspek pengetahuan, sikap, perasaan, serta perilaku terhadap Tuhan Yang Mahakuasa, sikap terhadap diri sendiri, lingkungan dimana seseorang tinggal bahkan terhadap negaranya (Afandi, 2011:87). 
Pendidikan karakter memiliki peran untuk mengembangkan kemampuan siswa agar berperilaku baik, sebagai wahana perbaikan budi pekerti, wahana penyaring kebudayaaan yang masuk baik budaya lokan maupun budaya asing yang bertentangan dengan nilai budi pekerti atau karakter bangsa.

Sastra lisan berupa cerita rakyat, mempunyai potensi dan peran sebagai sumber budaya yang dapat dikembangkan pada ranah pendidikan maupun kebudayaan. Pernyataan ini senada dengan pendapat Horace dalam Wellek dan Warren (1993:30), bahwa sastra berfungsi dulce et utile. Pembelajaran dengan berdasarkan aspek kearifan lokal daerah salah satunya dapat diwujudkan dengan mengangkat foklor sebagai materi pembelajaran.

Selama ini pembelajaran mengapresiasi karya sastra yang diajarkan oleh para guru di sekolah khususnya cerita rakyat, cenderung mengulang cerita yang sama atau cerita itu-itu saja. Padahal jika dikembangkan, banyak terdapat cerita rakyat di daerah-daerah, yang dapat diangkat dan dijadikan materi pembelajaran. Tindakan ini merupakan sebuah langkah dan strategi untuk dapat memperkenalkan dan menggali nilai-nilai khasanah budaya daerah, sekaligus untuk melestarikan bentuk budaya yang merupakan aset kebudayaan nasional.

Untuk memahami secara langsung nilainilai budaya itu sendiri salah satunya dapat melalui bahasa, mengingat salah satu fungsi bahasa adalah sebangai penyimpan norma budaya yang tercermin melalui kosa kata, pantun, cerita rakyat, nyanyian, ungkapan, dan sebagainya.

Berdasarkan paparan di atas penelitian ini penting untuk dilakukan, mengingat fungsi cerita rakyat atau folklor memiliki kaitan erat dengan pembentukan karakter bangsa Indonesia. Salah satu folklor jarang diketahui oleh masyarakatnya sendiri adalah sebuah cerita dari Gunungkidul dengan judul Nyi Andan Sari dan Ki Guru Soka. Cerita ini merupakan cerita rakyat masyarakat Gunungkidul dengan tema pengabdian yang mengisahkan kehidupan keluarga tokoh tersebut, sehingga mereka bisa memiliki hunian sendang (danau). Dalam cerita itu pula, digambarkan secara umum, tidak rinci. Memiliki kekhasan dengan menyebutkan tempat-tempat yang terdapat di Gunungkidul.

Penelitian sejenis pernah dilakukan oleh Novika Malinda Safitri. Fokus penelitian tersebut adalah penerapan pendidikan karakter melalui kultur sekolah. Hasil penelitiannya membuktikan bahwa kultur sekolah sangat berperan penting dalam proses internalisasi karakter di sekolah. Sementara dalam penelitian ini, dipusatkan pada kajian pendidikan karakter dalam cerita rakyat yang merupakan salah satu bentuk dari kearifan lokal daerah. Kajian mengenai cerita rakyat ini dilakukan agar muatan nilai karakter yang terdapat di dalamnya dapat dideskripsikan.

\section{METODE PENELITIAN}

Penelitian mengenai kajian pendidikan karakter dalam cerita rakyat dari Gunungkidul ini adalah penelitian kualitatif deskriptif. Penelitian kualitatif adalah penelitian yang menghasilkan data deskriptif berupa kata-kata tertulis atau lisan dari orang-orang atau perilaku yang diamati (Moleong, 2016:4). Data penelitian berupa dokumen cerita rakyat berjudul Nyai Andan Sari dan Ki Guru Soka dan wawancara dengan informan yang kemudian ditranskrip menjadi bahasa tulis. Penelitian ini mendeskripsikan informasi secara teliti dan analitis. Pengumpulan data dilakukan dengan cara mengkaji teks, melakukan pencatatan, analisis dan wawancara. Analisis data menggunakan analisis interaktif yang merupakan interaksi dari empat komponen penelitian yakni; (1) pengumpulan data, (2) reduksi data, (3) penyajian data, (4) penarikan simpulan. Validitas data diperoleh melalui triangulasi metode dan review informan.

\section{HASIL PENELITIAN DAN PEMBAHASAN}

Kekayaan budaya nenek moyang kita merupakan warisan budaya yang sarat akan nilai kearifan lokal. Budaya tersebut berkembang secara turun temurun dan menjadi modal dasar untuk membentuk jati diri dan karakter suatu bangsa (Alfian, 2013: 424). Nilai budaya di sebuah wilayah sangat dominan dan kuat tertanam pada diri seseorang sehingga membentuk karakter seseorang . Nilai tersebut tercermin mealalui tuturan, tindakan dan tertanam dalam pola pikir dan pembuatan keputusan seperti dikatakan oleh Ferdiawan dan Wira Eka Putra (2013: 1097) "Cultural value of the area are very strong and dominant in shaping a person's character". "Cultural values will be reflected in very word, action and will be 
ingrained in humans, including in thinking and making decisions".

Nilai-nilai tesebut diantaranya dapat terlihat melalui tradisi, budaya bahkan bahasa. Folklor adalah warisan nenek moyang kita. Folklor di Indonesia meliputi (1) bahasa rakyat, (2) ungkapan tradisional, (3) pernyataan tradisional, (4) sajak dan puisi rakyat, (5) cerita prosa rakyat, dan (6) nyanyian rakyat (Danandjya, 2002:22). Cerita Nyi Andan Sari dan Ki Guru Soka termasuk dalam foklor karena termasuk dalam jenis cerita prosa rakyat.

Cerita atau kisah Nyi Andan Sari dan $\mathrm{Ki}$ Guru merupakan salah satu folklor yang berkembang dari Kabupaten Gunungkidul. Menurut Danandjaya (2002:2) folklor adalah kegiatan kebudayaan secara kelompok, menyebar, diwariskan dari generasi ke generasi, bersifat tradisional yang dikemas dalam versi yang beragam baik berbentuk lisan maupun berupa gerak isyarat. Dari ciri yang disebutkan ini nyatalah bahwa cerita Nyi Andan Sari dan Ki Guru Soka termasuk dalam kategori folklor.

Pernyataan di atas dapat dibuktikan dengan melihat kenyataan bahwa cerita tersebut hingga kini masih dikenal oleh masyarakat di sana. Dari informan $\mathrm{CH}$ didapatkan data bahwa masyarakat Kabupaten Gunungkidul masih sangat mengenal cerita rakyat yang satu ini. Melalui informan juga didapati data bahwa cerita rakyat ini mengandung banyak muatan pendidikan budi pekerti atau karakter.

Dari kajian pada naskah cerita rakyat tersebut, peneliti mencoba untuk memetakan muatan pendidikan karakter yang bisa ditemukan dari kisah tersebut. Dasar pemetaan berdasarkan pedoman dari Puskurbuk, didapatkan ada sepuluh nilai karakter.

\begin{tabular}{cl}
\hline No & $\begin{array}{r}\text { Nilai Pendidikan } \\
\text { Karakter }\end{array}$ \\
\hline 1 & Religius
\end{tabular}

2 Toleransi

3 Disiplin

4 Kerja keras

5 Mandiri

6 Rasa ingin tahu
Cuplikan Cerita

a. Ki Guru Soka bertekad bulat pergi "nenepi", memohon petunjuk supaya kehidupan dalam rumah tangganya menjadi lebih baik. Niat bertapa Ki Guru Soka itu segera dilaksanakan.

b. Di dalam pertapaannya, ia mendapatkan godaan dalam berbagai bentuk, namun dengan niat untuk mencari ridho Tuhan, akhirnya ia berhasil menyelesaikan dan melewati godaannya,

a. Andan Sari mengatakan bahwa ia akan pulang ke sendang yang telah diperuntukkan baginya, yakni sendang yang berada di urutan kedua yang terakhir.

b. Ketika ada tamu yang berkunjung ke sendang Mole maupun Sendang Beji, jika mereka berbuat senonoh, ganggulah, namun usahakanlah jangan sampai mereka meninggal dunia.

Kyai Soka dan Andan Sarii menuruti petunjuk dan arahan ayahandanya berkeliling menghitung sendang di Gunungkidul.

a. Setelah beberapa bulan lamanya, Guru Soka meninggalkan anak dan istrinya untuk pergi bertapa.

b. Mengingat mereka tidak mengetahui keberadaan Kyai Guru Soka, maka arah perjalanan mereka hanya dikira-kira saja. Namun setelah beberapa hari mereka perjalanan mereka, akhirnya mereka menemukannya. Saat keluarga Nyai ditinggalkan suaminya, Nyai berusaha menghidupi keluarganya sendiri tanpa bantuan Kyai Guru Soka

Andan Sari dan suaminya sangat ingin mengetahui apa yang seharunya dilakukannya di dua sendang tersebut. Termasuk ketika beberapa orang yang 
Yustina Dwinuryati \& Andayani

7 Semangat kebangsaan

8 Bersahabat

9 Peduli sosial

10 Tanggung Jawab memiliki niat jahat melakukan hal yag senonoh maka kewajiban mereka untuk selalu mengingatkan.

a. Suatu hari Guru Soka menyuruh kedua anaknya supaya mereka menjelajahi dan menghitung semua sendang yang terdapat di daerah Gunungkidul. Apabila mereka telah mengetahui jumlah sendang, maka mereka berdua diwajibkan untuk menetap beberapa lamanya di sendang urutan kedua terakhir.

b. Suami istri itu kemudian berangkat untuk menjalankan amanah ayahanda mereka agar menemukan jumlah sendang yang ada di Gunungkidul.

Seandainya di tempat tinggalmu kamu menemukan sesamamu yang melakukan perbuatan tidak senonoh dan tidak sopan, ataupun kurang menghormati tempatmu ini, maka ganggulah mereka, namun jangan sampai mereka mati, sebab apabila mereka mati, mereka tidak memberimu sandang dan pangan.

a. Tempatmu berada kini, suatu saat akan dikunjungi oleh banyak orang. Beberapa di antara akan memohon agar permintaannnya dikabulkan.

b. Namun ada pula orang yang datang namun bertindak sembrono dengan tidak mematuhi aturan yang berlaku di sini. Dari mereka inilah nanti kalian akan memperoleh sandang dan pangan. Berbuat jahillah kepada orang-orang yang berbuat sembrono ini.

a. Maka Soka pun berkata kepada istrinya: "Sudahlah jangan cemaskan aku”. "Mulai saat ini kalian akan menunggu tempat ini, Aku lah yang akan bertanggung jawab mencari nafkah untuk anak kita serta untukmu, Nyi"

b. Kedua suami istri itu kemudian bergegas berangkat mencari keberadaan anak-anak mereka di setiap sendang yang mereka lewati.
Dari analisis di atas, akhirnya ditemukan sepuluh karakter yang ditemukan dalam cerita tersebut. Karakter yang ditemukan yaitu religius, toleransi, bersahabat, disiplin, mandiri, kerja keras, peduli sosial, mandiri, keingintahuan yang kuat, semangat kebangsaan, serta tanggung jawab.

Tentunya setiap karakter yang muncul bermula dari cerita yang digambarkan pada folklore tersebut. Nilai religious dilihat dari kebersediaan bertapa oleh Ki Guru Soka untuk menemui Tuhan agar mendapatkan pencerahan dalam kehidupannya. Meskipun dalam pertapaannya tersebut ia mendapatkan berbagai ancaman, godaan, gangguan dari berbagai bentuk, ia tetap memiliki kekuatan hati untuk melihat ke depan dan tujuannya. Hal ini patut dicontoh, karena ada kecenderungan manusia saat ini yang sudah tidak tahan godaan, seperti halnya korupsi, pembunuhan, pemerkosaan, dan bentuk kejahatan lainnya. Sebagian dari itu mampu menunjukkan ketidakkuatan pada segala sesuatu yang hanya sekadar bersifat duniawi.

Nilai pendidikan lainnya adalah toleransi, sebenarnya pada nilai toleransi yang ditemukan juga memiliki kemiripan dengan kekeluargaan. Dalam hal ini, sikap seorang Andan Sari yang mengantarkan adiknya sampai sendang yang terakhir, dan ia bersedia kembali ke sendang sebelumnya, agar adiknya tidak perlu berpindah ke satu sendang sebelumnya. Ini sama dengan kekuatan keluarga, yang menjadi konteks saat ini 
adalah, keluarga bukan lagi figur yang nyaman untuk mengembangkan kepribadian. Keluarga seolah-olah mulai acuh dengan saudara yang lainnya. Ini menunjukkan ketidakharmonisan dan koneksi yang buruk.

Di dalam cerita ini ditemukan juga nilai disiplin. Kedisiplinannya antara lain pada cuplikan saat Nyai Andansari dan Kyai Soka mendapatkan amanah dari orang tuanya untuk menghitung berapa sendang yang terdapat di Gunungkidul. Hal ini tentunya bentuk disiplinitas, karena jarang sekali anak jaman sekarang yang ketika disuruh melakukan pekerjaan yang berat, bersedia melakukan dengan ikhlas. Dari sini pula muncul nilai karakter kerja keras. Kerja keras dalam cerita ini ditunjukkan dengan peristiwa pencarian sendang, sama seperti pada kedisiplinan namun setelah kedisplinan serta tekad kuat untuk melakukan pekerjaan tersebut. Menghitung sendang sebuah pekerjaan berat, dalam cerita jawa, menghitung sendang sama sulitnya dengan menghitung gunung. Karena dengan melakukan kedua hal tersebut, orang dapat dikatakan memiliki kekuatan magis.

Seperti halnya nilai karakter lainnya, ditemukan pula mandiri, nilai mandiri yang ditemukan adalah ketika keluarga yang miskin tersebut ditinggal oleh Kyai Guru Soka, maka keluarga tersebut masih bisa bertahan oleh kemandirian. Mandiri dalam hal ini berarti kemampuan bertahan hidup dari keadaan di sekeliling. Kemandirian tersebut menjadi gambaran bagi masyarakat dewasa ini, agar mereka memiliki keberanian untuk berubah menjadi anak yang mandiri. Karena kemandirian menjadi bekal pribadi kuat, berbudi luhur dan menjadi teladan bagi seorang anak.

Ditemukan pula nilai keingintahuan yang kuat, peduli sosial, semangat berkebangsaan, bersahabat, dan tanggung jawab. Nilai keingintahuan yang kuat ditunjukkan ketika kedua anaknya ingin tahu keberadaan sang ayah, dan pada akhirnya nanti mereka akan mencari keberadaan ayahnya ke tempat bersemedi. Juga semangat kebangsaan yang ditemukan dari penemuan sendang oleh nyai dan kyai Andan Sari. Mereka telah berhasil menemukan jumlah sendang yang terdapat di Gunungkidul. Merupakan sebuah penemuan yang luar biasa, dua orang yang biasa saja bisa menemukan dan menjadikan itu sejarah yang terkenang.

Nilai bersahabat, ditemukan dalam dialog antara kedua anak tersebut dengan Kyai Guru Soka, yang menceritakan dan mewasiatkan agar mereka nantinya bersahabat dengan masyarakat sekitar tempat tersebut. Asalkan mereka tidak mengganggu, maka Nyai Andansari dan Kyai Soka dilarang menggangu orang itu.

Deskripsi di atas membuktikan bahwa $K i$ Guru Soka ingin agar anaknya mampu membaur dan bersahabat dengan masyarakat di sekitar tempat tinggalnya. Melalui cerita ini sekaligus mampu menjawab persoalan kepedulian sosial, karena diceritakan bahwa Kyai Soka mengharapkan anaknya untuk membantu dan mengabulkan permintaan warga yang membutuhkan di daerah tempat tinggalnya.

Nilai bertanggung jawab ditunjukkan dengan perlakuan Guru Soka yang selalu memantau perkembangan anaknya, selain itu Kyai juga berjanji untuk mencari nafkah untuk anak-anaknya. Sebagai seorang bapak, Kyai akan terus menanggung seluruh kebutuhan dari keluarga tersebut.

\section{SIMPULAN}

Terdapat sepuluh nilai karakter dalam cerita rakyat Nyi Andan Sari dan Ki Guru Soka yang mampu mendidik generasi muda dalam bertingkah dan bertutur. Perilaku yang ditunjukkan untuk membantu masyarakat yang membutuhkan yang tercermin dalam diri tokohtokoh cerita dapat membuka wawasan dan cara pandang keduniaan manusia.

Harapan peneliti semoga hasil penelitian ini dapat dipakai sebagai wawasan para guru dalam menentukan materi pembelajaran sastra. Penggunaan cerita rakyat sebagai bahan untuk pendidikan karakter juga merupakan salah satu bentuk pelestarian budaya daerah. Perlu menjadi contoh, ketika masyarakat tidak peduli lagi terhadap lingkungan, maka Gunungkidul mampu menawarkan folklor yang mendidik karakter, moral, dan kepribadian bangsa. Generasi muda jelas membutuhkan semangat dan spirit cerita rakyat. Meskipun beberapa terkesan sangat fiktif dan tidak bisa dinalar, cerita rakyat merupakan bagian dari kebudayaan yang terlestari dengan baik.

\section{DAFTAR PUSTAKA}

Afandi, Rifki. 2011. "Integrasi Pendidikan Karakter dalam Pembelajaran IPS di Sekolah Dasar". dalam Jurnal Pedagogia Vol I (1). Halaman 85-98. 
Alfian, Magdalia. 2013. "Potensi Kearifan Lokal dalam Pembentukan Jati Diri dan Karakter Bangsa". dalam Prosiding ICSSIS (International Conference on Indonesian Studies) di Yogyakarta Tanggal 13-14 Juni 2013.

Astra, I Gde Semadi. “ Revitalisasi Kearifan Lokal dalam Memperkokoh Jati Diri Bangsa di Era Global" dalam I Wayan Ardika dan Dharma Putra (ed) . Politik Kebudayaan dan Identitas Etnik. Denpasar: Fakultas Sastra Universitas Udayana dan Balimangsi Press.

Danandjaya, James. 2002. Foklor Indonesia. Jakarta: Pustaka Utama.

Dirman dan Cicik Junarsih. 2014. Kegiatan Pembelajaran yang Mendidik. Bandung: Rineka Cipta.

Departemen Pendidikan dan Kebudayaan. 2008.KBBI. Jakarta: Balai Pustaka.

Ferdiawan, Erick and Wira Eka Putra. 2013. "Esq Education for Character Building Based on Phylosophy of Javaness in Indonesia. dalam Procedia Vol 106. Halaman 1096-1102.

Ilahi, Mohammad Takdir. 2014.Gagalnya Pendidikan Karakter. Yogyakarta: ArRuz Media.

Kesuma, Triatna, Permana. 2013. Pendidikan Karakter, Kajian Teori dan Praktik di Sekolah. Bandung: PT Remaja Rosdakarya.

Marsono. 2007. "Revitalisasi Kearifan Lokal Guna Mewujudkan Masyarakat Sejahtera" dalam Jurnal Kemajuan Terkini Riset Universitas Gajah Mada. Yogyakarta: LPPM UGM. 
Jurnal Artefak: History and Education, Vol.4 No.1 April 2017 